\begin{tabular}{c} 
Volume and Issues Obtainable at Center for Sustainability Research and Consultancy \\
Journal of Business and Social Review in Emerging Economies \\
ISSN: 2519-089X (E): 2519-0326 \\
Volume 6: No. 3, 2020 \\
CSRᄃ \\
Journal homepage: www.publishing.globalcsrc.org/jbsee \\
\hline
\end{tabular}

\title{
Assessing the Academic integrity among University Students in Pakistan
}

\author{
${ }^{1}$ Anwar Ul Haq, ${ }^{2}$ Sadaf Mahmood, ${ }^{3}$ Muhammad Shabbir, ${ }^{4}$ Zahira Batool \\ ${ }^{1} \mathrm{PhD}$ Scholar, Department of Sociology, GC University Faisalabad, Pakistan, Haqanwar11@gmail.com \\ ${ }^{2 \& 3}$ Assistant Professor, Department of Sociology, GC University Faisalabad, Pakistan, \\ sadaf.mahmood88@yahoo.com,drmshabbir@gcuf.edu.pk \\ ${ }^{4}$ Professor, Department of Sociology, GC University Faisalabad, Pakistan, batoolazam@ hotmail.com
}

\begin{abstract}
ARTICLE DETAILS
History

Revised format: August 2020

Available Online: September 2020
\end{abstract}

\section{Keywords}

Higher Education Institutions, Academic Integrity, Teacher's behavior, Academic Misconduct

\section{JEL Classification}

$\mathrm{MO}, \mathrm{I23}, \mathrm{I25}$

\begin{abstract}
The principal objective of this research was to assess the academic integrity among Pakistani university students. Qualitative data were obtained from 3 Focus Group Discussions (FGDs) with students from different universities. Mixed Methods Research was applied at the individual and group level and data were analyzed with the help of content analysis. The analysis unveiled four key themes including teacher's behavior in the classroom, teacher's evaluation method in Examinations, the influence of peer pressure, and the popularity of the memorization method among students. Students' level of satisfaction with teachers' behavior in the classroom and at the time of assessment of examination remained low and they considered it as the main reason behind their low level of academic integrity. Rote learning, inconsistencies in the examination evaluation method, and the effect of peer pressure were also identified as the central reasons behind their academic misconduct behavior. It is concluded that in the coming few years, academic misconduct is going to become a popular culture in Pakistani universities and it is a dire need to stop this behavior. Suggestions to overcome this problem are to trained students as well as teachers. The teacher's professional and moral training can directly effect on the training and moral values of students. This study was conducted in Pakistan, but the findings can be observed and replicated in higher education systems in many developing nations.
\end{abstract}

(C) 2020 Center for Sustainability Research and Consultancy Pakistan under a Creative Commons Attribution-NonCommercial-ShareAlike 4.0

Corresponding author's email address: drmshabbir@gcuf.edu.pk

Recommended citation: Haq, A., Mahmood, S., Shabbir, M., \& Batool, Z. (2020). Assessing the Academic integrity among University Students in Pakistan. Journal of Business and Social Review in Emerging Economies, 6(3), 10251032

\section{Introduction}

Academic integrity is a comprehensive phrase defined as a "set of shared values and ethics which include honesty, fairness, rigor, trust, and respect about students' academic work and its assessment" (Stephens, 2019; Macfarlane, Zhang, \& Pun, 2014). Concerns related to academic integrity are widespread around the globe (Peters, Boies, \& Morin, 2019). Ma et al., (2013) reported $83 \%$ of Chinese students admitted to some form of academic misconduct (Ma, McCabe, \& Liu, 2013). The International Center for Academic Integrity (ICAI) 2002 and 2015 reported 
shocking $95 \%$ of students in US colleges acknowledged academic misconduct (McCabe, 2020). Similarly, studies in Indian medical and paramedical colleges uncovered that $88 \%$ of the students observed cheating, however, only around $5 \%$ accepted of being involved (Gitanjli, 2004). A study by Hafeez et al., (2013) in Pakistan among medicine students also disclosed that 55\% accepted cheating in exams (Hafeez, Khan, Jawaid, \& Haroon, 2013). All these statistics confirm that students' behavior regarding academic integrity is a severe challenge to higher education in the contemporary world. Similarly, students have access to enormous amounts of data on the web which has blurred the boundaries between what is allowed and not allowed (Goldman \& Martin, 2016).

The research in academic integrity mostly focuses on three themes. First, the level of prevalence of misconduct (Ma, McCabe, \& Liu, 2013; McCabe, 2020), Second, the consequences of dishonesty for academia (Adam, Anderson, \& Spronken-Smith, 2017; Debbie Wheeler, 2010) and third are the methods to prevent academic misconduct (Caldwell, 2010). Most literature focuses on numbers and statistics of misconduct. Such types of empirical studies mostly report alarming figures of academic misconduct (McCabe, 2020; Hafeez, Khan, Jawaid, \& Haroon, 2013). Studies related to the consequences of dishonesty usually report the appalling conditions of university education and how plagiarism has deteriorated the quality of graduates (Bachore, 2016). While, studies related to the prevention of misconduct usually discuss models, strategies, and techniques to enhance academic integrity (Kumar, 2010). However, the broader causes of misconduct are rarely documented, especially with this question of why students cheat. So, this is a clear gap in the literature.

Studies related to misconduct, its consequences, and prevention, briefly, explores the causes of academic misconduct, however, an independent investigation of causes especially concerning student's perception and understanding of the teacher's behavior does not exist. It is widely reported by students and in empirical studies, that the teacher's role in shaping academic integrity is vital (Caldwell, 2010; Peters, Boies, \& Morin, 2019). Besides this, teachers are the first line of defense against academic misconduct (Keener, et al., 2019). Similarly, it was reported in a multi-method study that the best methods to prevent academic misconduct is through faculty training and support (Hill, 2010). Considering all these assumptions this study explores the causes of academic misconduct. It investigates the role of students' experiences and understanding of the teacher's behavior and the university environment as a determinant of their academic integrity. The focus of the study was on external factors that how students' morality is shaped by the environment.

Two crucial terms academic integrity and academic misconduct are interchangeably used in this article. Academic integrity can be defined in several ways and there is less agreement over what constitutes academic integrity (Fishman, 2016; McCabe, 2020). Bruce Macfarlane defined academic integrity as a mixture of values, behavior, and conduct in all aspects of academic life (Macfarlane, Zhang, \& Pun, 2014). Academic integrity as a phrase has many interpretations. In one way, it is a combination of values, behavior, and conduct related to academic practice (Macfarlane, Zhang, \& Pun, 2014). Comparably, the word may refer to "honor codes at campuses", institutional expectations of student behavior, ethical education of professionals, and antonym of academic misconduct (Macfarlane, Zhang, \& Pun, 2014). So, various interpretations of the phrase academic integrity are possible. Jason Stephens 2019 defined academic integrity as a set of shared values and ethics which include honesty, fairness, rigor, trust, and respect about a student's academic work and its assessment (Stephens, 2019).

While academic misconduct is the opposite of academic integrity. Most studies on academic integrity report academic misconduct. Academic misconduct includes but is not limited to plagiarism, collusion, ghostwriting, cheating in exams, and copy-pasting materials from the internet (Eaton, 2017). In short academic misconduct refers to any activity which gives an unfair advantage to the students. It includes unfair advantages in exams, assignments, research, or any other assessment activity (Eaton, 2017).

\section{Theoretical Framework}

This study explored the students' experiences and understanding of academic integrity. These experiences, perceptions, and observations shape students' attitudes and behavior. This study is theoretically organized by the sociology of morality and norm circles theory. Sociology of morality considers few assumptions, one, that morality despite biological explanations, has social complexity and cultural diversity (Bykov, 2018), Two, morality has 
components that are external to one's body (Wong, 2006), and three morality is not only about norms and values (Hitlin \& Vaisey, 2013). Sociology of morality includes narratives, identities, institutions, symbolic boundaries, and cognitive schemas, (Hitlin \& Vaisey, 2013). In this study, external factors of a moral decision "Academic integrity" are identified. How these experiences of students are shaping their views of honesty, responsibility, and ethics. The evidence from data is parallel to the theory of morality. The theoretical assumptions and their compatibility with data are discussed in the qualitative analysis as well. The second model is also close to morality and refers to the assumption that "norms" are group-based behavior (Vass, 2010). Norms and values are shared among the groups (Vass, 2010). Like morality, norms are also derived from the group of a person he belongs to. In this context, students' norms are derived from their peers. The role of peers as a role model is discussed in the section where the effect of peer pressure is examined. So, it can be epitomized that external social factors determine or at least influence academic integrity behavior. As for socialization, social construction, and sociological imagination, all can relate to assumptions of externality, so this study has broader implications for the sociological study of academic integrity.

\section{Objective of the Study}

The core objective of the study was to assess the level of academic integrity of students in the university settings and to identify the factors that affect on their level of academic integrity.

\section{Research Methodology}

This qualitative research draws on Focus Group Discussions (FGD) as a technique of data collection. Three focus group discussions with students from distinct universities were conducted. The first FGD was conducted at Punjab University with 11 students. The second focus group was conducted with 10 students of Government College University Faisalabad. The third focus group discussion was conducted with 8 students of International Islamic University Islamabad. All the students were in the final semester of their degree (8th semester of BS or 4th semester of Masters). Students from last semesters were selected purposely because they know about the university environment through their experience. The background details of respondents in each focus group are discussed in the table below. These Focus Group Discussions were audio-recorded and then transcribed. This transcription of audio files yielded a bulk of data, around 150 pages. This Data was analyzed using mixed methods of content analysis. During the analysis of FGDs, the individual responses were analyzed as well as the impacts of the group on the opinion were also considered. The chunks of codes developed during the analysis were compared individually, as well as their presence in the group was measured. The content analysis was applied at the level of the individual as well as at the group level. The individual analysis helped the researcher to explore the in-group patterns, while group analysis helped to explore the patterns among universities. These experiences and understanding of the students create their meaning and practices regarding academic integrity, so their understandings reflect social meaning and hence social construction. During the FGDs students were asked various questions related to academic integrity. However, the questions and further probing were more focused on questions of examination, quality of education, students' and teacher's role and their behavior in class, and examinations. Students could express their understanding before asking any further probing questions. Some of the probe questions also asked about the percentage of the mentioned act. Semantic content analysis was used to produce a list of occurrences of themes. In semantic content analysis occurrences and meaning inherent in the text, both are reported (Onwuegbuzie, Dickinson, Leech, \& Zoran, 2009). These themes are then used to assert the meaning obtained from the data. The themes are reported with explanations from the original data. The four key themes/codes that emerged from the data are discussed in the table below:

\section{Table 1: Major themes, sub themes and examples that how students describe these themes}

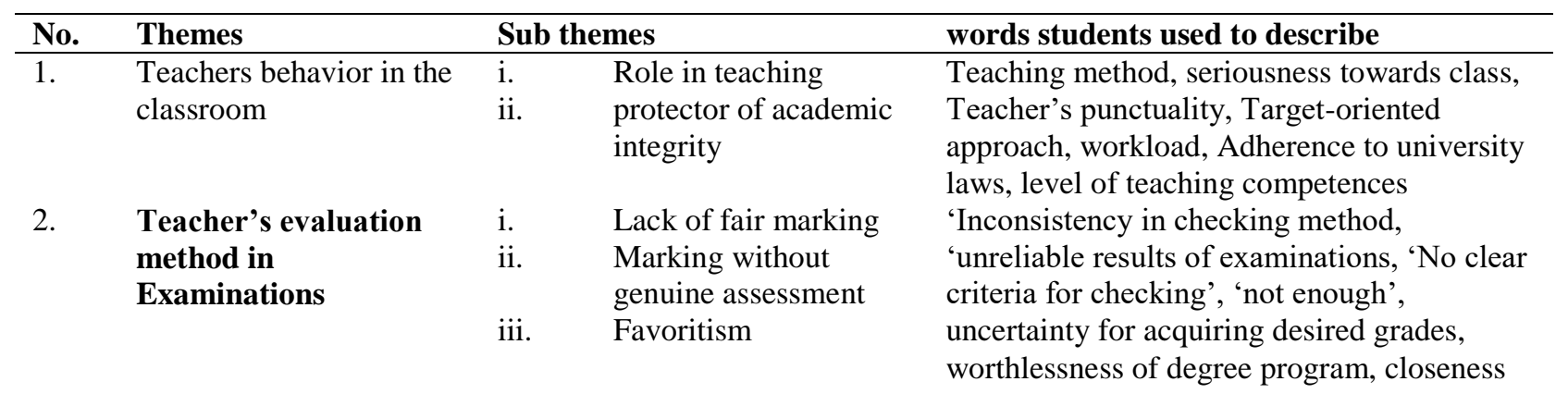




\begin{tabular}{|c|c|c|c|}
\hline 3. & $\begin{array}{l}\text { The popularity of the } \\
\text { memorization method } \\
\text { among students }\end{array}$ & $\begin{array}{l}\text { i. } \\
\text { ii. }\end{array}$ & $\begin{array}{l}\text { Lack of practical work } \\
\text { Lack of conceptual } \\
\text { study }\end{array}$ \\
\hline & & iii. & Lack of \\
\hline & $\begin{array}{l}\text { The influence of peer } \\
\text { pressure }\end{array}$ & i. & $\begin{array}{l}\text { Influence on each } \\
\text { other }\end{array}$ \\
\hline & & ii. & $\begin{array}{l}\text { Influence on whole } \\
\text { environment }\end{array}$ \\
\hline
\end{tabular}

to teacher, students' request and begging for marks and grades,

Writing word to word from given material,

Rote learning, No conceptual work, verbatim true answers

Cheating, no strict punishment to control cheating, Sympathetic behavior towards students' future if they caught while cheating, everyone submits copy-paste assignments why not me, collusion, plagiarism

\subsection{Teacher's Behavior in Classroom}

Teacher's behavior in the classroom is an important factor for students' morality. It was found in a previous study in the USA, that student's perceptions of lower difficulty and lesser workload compel them to misconduct and cheat. Students in such courses are more likely to cheat (McKibban, 2013). Similarly, in this study during all focus group discussions, students reported that the teacher's seriousness towards academic activities is a deciding factor in academic misconduct. One female student in our FGDs stated that if a teacher focus to remove the plagiarism from assignments then we do it and all the other participants of the FGDs agreed with her. In all three focus group discussions, it was consistently disclosed by students that teachers' teaching method, his/her seriousness towards class, Teacher's punctuality, and the target-oriented approach towards syllabus completion are all those factors that encourage or discourage the student's cheating behavior. Almost all students in three FGDs agreed that if the teacher's attitude towards class is non-serious, the class workload for students is more limited and the syllabus taught in the class is not up to the mark, then students are more likely to cheat in that specific course. The students mentioned the word "level" for this. They said that teachers' level of teaching shows their caliber and capacity of delivering information. Teacher's behavior in the classroom can be further divided into two sub-themes. First, the teacher's role is teaching courses, and second, the teacher's role as protectors of academic integrity. In the teachers' role in teaching students identified various issues. All students agreed that teachers who take their classes regularly, come on time, and are co-operative with students, in these classes students realize that this teacher will not compromise on academic misconduct. Students are less likely to be involved in cheating in the classes of these teachers. These findings are supported by previous studies on the university environment (Nadelson, 2006). In this regard, one female student even said that "I do not think that the teachers who are not serious in taking the classes, they even check the papers seriously". Similarly, another male student said that a teacher's level of teaching determines how they will evaluate the exams. So, the teacher's role in the classroom is the first thing that influences students' morality. The second subtheme is the teachers' role as protectors of academic integrity. It is thought that teachers are the first line of defense against academic misconduct (Keener, et al., 2019). Students' perceptions and experience depend on the teacher's level of commitment towards teaching, understanding students, and adherence to university rules and regulations. One student pointed out and others agreed that teachers should be co-operative. As far as evaluation rules are concerned, university protocols should be followed. This leads us to our second concern, which is the teacher's evaluation method of examinations including answer transcripts, assignments, presentations and class participation.

\subsection{Teacher's Evaluation Method in Examinations}

The second theme that was most resonant in all the FGDs was teachers' evaluation and assessment of students' work and examination. It was found in an earlier study in China that teachers' fairness in academic evaluation and research is a critical factor in determining students' academic integrity (Macfarlane, Zhang, \& Pun, 2014). Students identified many problems in the evaluation system. Some of these problems are unique to the Pakistani context. In developing countries literature is not present, however; these problems are non-existent in the developed world. One problem that emerged with outrageous figures was non-checking of the assessment activities (assignments, presentations, mid-term examination, and final examination). Three major sub-themes related to evaluation emerged from the discussion. These themes were inconsistency and unfair checking of examinations and assessment, and favoritism (reported by majority of the students) towards few students. These three themes were the major justification that the students gave for their involvement in cheating behavior. In literature, it was found that students' justifications and perceptions 
towards this unfair behavior push them to academic misconduct (Stone, Jawahar, \& Kisamore, 2009). One male student said that "I feel depressed and sometimes tense because I am not sure I will get good marks even after studying and attempting good paper". Students in all FGDs showed this concern that there is no uniform system of evaluation. The second sub-theme identified was favoritism and frequent interaction with the teachers. This problem is not yet identified in previous studies. It may be unique to the Pakistani context. It was reported by the students that intimacy to the teacher or frequent requests for good grades and consistent begging can help students to secure good marks. The most shocking theme that emerged was "grade distribution on the base of unchecked answer transcripts and assignments". Students perceive that around $70 \%$ of teachers do not check assignments. This perception and experience are shared among all three groups. This number is extremely high and needs serious investigation in future studies. Besides assignments, all students from three universities had experienced that $30 \%$ of the teachers showed careless attitude towards checking the answer sheets attempted by the students. Students perceive that non-checking of assignments and answer sheets are the unsaid norms that should be discouraged by the rules and regulations of the university. Students tried to hide their academic misconduct under the umbrella of these factors. Interestingly, one of the group members stated that teachers are interested in extra paid classes that increased their workload and they do not have enough time to justify each course. When this point was raised, the researcher further investigated and found that in literature, it has been reported that the concept of visiting teachers and taking more than the required workload is a norm in universities these days. Deteriorating quality of education, academic misconduct, and grade inflation were documented problems in literature (Ullah, 2018). This leads us to the third reason behind academic dishonesty that is the culture of memorization.

\subsection{The Popularity of the Memorization Method among Students}

The third theme that emerged from the data was the "culture of memorization" that compels students towards cheating. Often when asked for justification of cheating even the good students reported that when you forget "one word", "the first line" then asking one or two words or a line is not unethical. This justification itself shows the problems related to memorization. There are three important sub-themes in memorization. First is a lack of practical work, second is the lack of conceptual study and third is the lack of encouragement towards self-study from other sources. In a lack of practical work, students insist that there should be practical and field activities that will help them to adjust in their professional life. In the second sub-theme, the students discussed the issue of conceptual study versus rote learning. Research-based activities as stated by the students are less prevalent on campuses. The students feel disconnected from the contemporary world and said that their degree is worthless. This understanding of worthlessness leads them towards misconduct. This culture of memorization is also influenced by the demand for good grades. Students said that it is commonly perceived that a student with good grades and higher CGPA is a hard worker and intelligent and this feels often compels students to indulge in unfair means in examinations to achieve their task. The problem of getting good grades through unfair means and memorization/misconduct is reported in some previous studies (Ullah, 2018). Another problem is that there is no self-study or freedom to study. Students said that there is also no concept of self-study. One female student said that teachers "give us notes and tell us to memorize them". Students from all universities agreed that teachers give more importance to verbatim true memorization of notes then conceptual study.

\subsection{The Influence of Peer Pressure}

The fourth most common theme was the effect of peer pressure or group behavior. Almost all students agreed that peer pressure influences academic integrity. In this theme, students reported two major ideas: one peers' influence on each other and two influence on the overall moral environment. These factors contribute to a student's academic integrity. Many students reported that they indulged in cheating behavior when they saw others around them were also cheating. One of the students said that "when I joined the university I promised that I will never use unfair means for good grades but when I saw everybody around me was easily getting things done, then sometimes I also took advantage of the situation". Most students agreed that when exposed to widespread cheating a person is compelled to join the group or happily become part of it. The first factor that peers influence the behavior of others is the most prevalent themes reported in academic integrity literature (Ma, McCabe, \& Liu, 2013; McCabe, 2020). Students help each other in cheating, collusion, plagiarism, etc. In the Pakistani context, a unique problem related to group activities was found that is one person completes the task and all other group members take the credit for that work. It was also found that students do not report any misconduct of their fellows, which creates a sense of obligation that when 
another person will be involved in misconduct, it will not be reported (Pupovac, Popović, \& Blažina, 2019). This culture of misconduct then becomes the norm and morality of the whole organization. As morality theory dictates that actors derive their morality from institutions and organizations, this becomes the unconscious self-schema of organizations (Hitlin \& Vaisey, 2013).

\section{Discussion}

All the four themes discussed above collectively develop a culture of misconduct and decrease academic integrity among university students. Students reported it repeatedly and teachers also agreed with this privately and some openly that academic misconduct in our higher education has become a norm (Hoodbhoy, 2015). It is difficult to report but this culture of misconduct in Pakistani universities mainly stems from teacher's behavior. This experience of students is widespread that teachers are not regular in class; they do not check the assignments and are not fair in their evaluation methods. This insight is very strong and shared among all the students. When, this insight is combined with low-quality teaching, poor administrative facilities, peer pressure, environmental influence, memorization-based examinations, lack of practical work, and no check and balance on all these activities that promote the culture of misconduct. This culture of misconduct and the use of unfair means for getting good grades discourage brilliant students and honest teachers for accomplishing their duties properly and honestly. These four themes were identified as major pieces of the puzzle. To solve the problem of academic misconduct there is a need to address all areas mentioned in the thematic domain, working only in one direction will not be sufficient.

\section{Conclusion and Recommendations}

Student's behavior regarding academic integrity is a severe challenge to higher education in Pakistan. This study was conducted to identify the possible factors affecting the academic integrity of university students. It was found that four major factors challenging the academic integrity of students and force them for academic misconduct. These are teacher's behavior in the classroom, teacher's evaluation method in Examinations, the influence of peer pressure, and the popularity of the memorization method among students. Students feel that the focus of teacher's and university curriculum is more on rote learning and less on the conceptual study and practical work. These factors combine to form a culture of academic misconduct and students took cheating and plagiarism as normal acceptable behavior. When there is extensive misconduct in universities, unconsciously people start to accept it. This leads to various social evils such as worthlessness of degree programs, grade inflation, and acceptance of dishonesty in social life. The university does not provide the skills and abilities as provided in international universities of developed countries. This situation leads to concerns related to human capital produced by universities. This obstacle has no single dimension; it is rooted in the broader culture of the university. To increase academic integrity, there is a need to work on all these themes. The first step to be taken in this direction is bringing morality back into the system of universities. The courses on ethics and professionalism; and pieces of training and sessions related to academic integrity should be organized by institutions for both the students and the teachers. Teachers must be given clear instructions about academic misconduct and how they can report it. Forums that tackle the causes of misconduct need to be vigilant and careful. The study also found that there is a lack of research related to academic integrity in the Pakistani context. Only a few research articles (as per researchers' knowledge) exist to this date in the Pakistani context on this widespread issue. Future researches need to investigate this problem from policy to individual psychological moral reasons.

\section{References}

Adam, L., Anderson, V., \& Spronken-Smith, R. (2017). 'It's not fair': policy discourses and students understandings of plagiarism in a New Zealand university. Higher Education, 74, 17-32. doi:https://doi.org/10.1007/s10734016-0025-9

Bachore, M. M. (2016). The Nature, Causes and Practices of Academic Dishonesty Cheating in Higher Education: The Case of Hawassa University. Journal of Education and Practice, 7(19), 14-20. Retrieved from http://www.iiste.org/

Bykov, A. (2018). Rediscovering the Moral: The 'Old' and 'New' Sociology of Morality in the Context of the Behavioural Sciences. Sociology, 1-16. doi:10.1177/0038038518783967 
Caldwell, C. (2010). Ten-step model for academic integrity:Positive approach for business schools. Journal of Business Ethics, 92, 1-13.

Cambridge Dictionary. (2020, 6 10). Cambridge Dictionary. Retrieved from Cambridge university: https://dictionary.cambridge.org/dictionary/english/academic

Debbie Wheeler, D. A. (2010). Dealing with plagiarism in a complex information society. Education, Business and Society: Contemporary Middle Eastern Issues, , 3(3), 166-177. doi:doi.org/10.1108/17537981011070082

Eaton, S. E. (2017). Comparative Analysis of Institutional Policy Definitions of Plagiarism: A Pan-Canadian University Study. Interchange, 48, 271-281. doi:https://doi.org/10.1007/s 10780-017-9300-7

Fishman, T. T. (2016). Academic Integrity as an Educational Concept, Concern, and Movement in US Institutions of Higher Learning. In Handbook of Academic Integrity. Singapore: Sprnger. doi:https://doi.org/10.1007/978981-287-098-8_1

Gitanjli, B. (2004). Academic dishonesty in Indian medical colleges. Journal of Postgraduate Medicine, 50(4), 281284.

Goldman, Z. W., \& Martin, M. M. (2016). Millennial students in the college classroom: adjusting to academic entitlement. Communication Education, 65(3), 365-367. doi:10.1080/03634523.2016.1177841

Hafeez, K., Khan, M. L.-u.-Z., Jawaid, M., \& Haroon, S. (2013). Academic misconduct among students in Medical Colleges of Karachi, Pakistan. Pakistan Journal of Medical Sciences Online, 29(3), 699-702. doi:dx.doi.org/10.12669/pjms.293.3300

Hill, C. (2010). Promoting Academic Integrity in Online Education. Wisconsin: Magna Publishers. Retrieved from https://www.daytonastate.edu/onlinestudies/files/Academic\%20Integrity\%20in\%20Online\%20Education.pdf

Hitlin, S., \& Vaisey, S. (2013). The New Sociology of morality. Annual Review of Sociology, 39, 51-68. doi:10.1146/annurev-soc-071312-145628

Hoodbhoy, P. (2015, November 21). Enough PhD's, thank you. Retrieved from The Dawn: https://www.dawn.com/news/1221057

Keener, T. A., Peralta, M. G., Smith, M., Swager, L., Ingles, J., Wen, S., \& Barbier, M. (2019). Student and faculty perceptions:appropriate consequences of lapses in academic integrity in health sciences education. BMC Medical Education, 1-9. doi:doi.org/10.1186/s12909-019-1645-4

Kumar, M. N. (2010). A theoretical comparison of the models of prevention of research misconduct. Accountability in Research, 17(2), 51-66. doi:10.1080/08989621003641132

Ma, Y., McCabe, D. L., \& Liu, R. (2013). Students' academic cheating in chinese universities: prevalence, influencing factors, and proposed action. Journal of academic ethics, 169-84. doi:10.1007/s10805-013-9186-7

Macfarlane, B., Zhang, J., \& Pun, A. (2014). Academic integrity: a review of the literature. Studies in Higher Education, 339-358. doi: doi.org/10.1080/03075079.2012.709495

McCabe, D. (2020, 06 26). Statistics. Retrieved from International Center for Academic Integrity : https://www.academicintegrity.org/statistics/

McKibban, A. R. (2013). Students' Perceptions of Teacher Effectiveness and Academic Misconduct:An Inquiry into the Multivariate Nature of a Complex Phenomenon. Ethics \& Behavior, 23(5), 378-395. doi:10.1080/10508422.2013.787918

Nadelson, S. (2006). The Role of the Environment in Student Ethical behavior. Journal of College and Character,, 7(5), 1-10. doi:https://doi.org/10.2202/1940-1639.1195

Najeeb, Z. (2020, july 1). Brain drain or academic asylum. Retrieved from Pakistan Today: https://www.pakistantoday.com.pk/2020/06/30/brain-drain-or-academic-asylum

Onwuegbuzie, A. J., Dickinson, W. B., Leech, N. L., \& Zoran, A. G. (2009). A Qualitative Framework for Collecting and Analyzing Data in Focus Group Research. International Journal of qualitative methods, 1-21.

oxford dictionary. (2020, 6 10). integrity noun from the Oxford Advanced Learner's Dictionary. Retrieved from Oxford learners dictionaries: https://www.oxfordlearnersdictionaries.com/definition/english/integrity?q=integrity

Peters, M., Boies, T., \& Morin, S. (2019). Teaching academic integrity in Quebec universities: roles professors adopt. Frontiers in education, 4, 1-13. doi:10.3389/feduc.2019.00099

Pupovac, V., Popović, S., \& Blažina, V. (2019). What Prevents Students from Reporting Academic Misconduct? A Survey of Croatian Students. Journal of academic ethics, 1-12. doi:doi.org/10.1007/s10805-019-09341-5 
Stephens, J. M. (2019, October 10). Academic Integrity: Values, Skills and action, The University of Auckland. Retrieved from Future Learn: https://www.futurelearn.com/courses/academic-integrity/20/steps/586489

Stone, T. H., Jawahar, I., \& Kisamore, J. (2009). Using the theory of planned behavior and cheating justifications to predict academic misconduct. Career Development International, 14(3), 221-241. doi:10.1108/13620430910966415

Ullah, H. (2018, September 2). Academic Grade Inflation in Pakistan: Sweet Poison. Paksitan Observer, p. 7.

Ullah, H. (2018, April 19). Teachers and the future of higher education. Retrieved from Daily Times: https://dailytimes.com.pk/229731/teachers-and-the-future-of-education/

Vass, D. E. (2010). The Causal Power of Social Structures; Emergence, Structure and Agency. Cambridge: Cambridge university press.

Wong, D. B. (2006). Moral Reasons: Internal and External. Philosophy and Phenomenological Research, 72(3), 536558. Retrieved from www.jstor.org/stable/40040949 